\title{
Immunohistochemical localization of adropin in the small intestine of rats
}

\author{
MARTA PAWŁOWSKA-OLSZEWSKA, IWONA PUZIO, MAŁGORZATA KAPICA, \\ GRZEGORZ TYMICKI, WIESŁAW ŚLEBODA, MICHAŁ WÓJCIK**, ANNA ŚMIECH*
}

\author{
Department of Animal Physiology, Faculty of Veterinary Medicine, \\ University of Life Sciences in Lublin, Akademicka 12, 20-033 Lublin, Poland \\ *Sub-Department of Pathomorphology and Forensic Medicine, Faculty of Veterinary Medicine, \\ University of Life Sciences in Lublin, Głęboka 30, 20-612 Lublin, Poland \\ ${ }^{* *}$ Chair and Department of Biochemistry and Biotechnology, Medical University of Lublin, Chodźki 1, 20-093 Lublin, Poland
}

\section{Pawłowska-Olszewska M., Puzio I., Kapica M., Tymicki G., Śleboda W., Wójcik M., Śmiech A. Immunohistochemical localization of adropin in the small intestine of rats \\ Summary}

The aim of this study was to determine the occurrence and distribution of adropin (ADR) in the small intestine in control and gastrectomized rats. The study was carried out on 12 Wistar rats. Six control rats (SHO) underwent a sham operation. Six rats were subjected to gastrectomy (Gx); i.e. resection of the antrum and the glandular part of the stomach. Six weeks after the surgery, the rats were sacrificed. The duodenum and middle part of the jejunum were collected for immunohistochemical and immunofluorescence procedures. An immunopositive reaction to ADR was detected in the duodenum and jejunum, in crypts, and in enterocytes located along the entire length of the villi. Furthermore, more intense ADR immunoreactivity was observed in the crypts and villi of the duodenum than in the jejunum. The presence of adropin was also detected in the submucosa and muscularis externa of the duodenum and jejunum, in the cells of Brunner's gland of the duodenum, and in myenteric and submucosal plexus nerve. The ADR immunoreactivity in the crypts and villi in the duodenum and jejunum was lower in the Gx rats compared to the SHO rats. The ADR distribution in the duodenum and jejunum has also been confirmed in immunofluorescence studies. In conclusion, our data demonstrated ADR expression in all histological layers of the small intestine in the rats. Gx reduced ADR immunoreactivity in the crypts and enterocytes. This may suggest a potential impact of ADR on intestine function such as absorbability and immune reactions. However, further research is needed to explain the ADR role in gastrointestinal functions.

Keywords: adropin, rat, small intestine, immunohistochemistry, immunofluorescence, gastrectomy

Adropin (ADR) was identified as a new regulatory peptide by Kumar et al. in 2008 (16). It is encoded by the Energy Homeostasis Associated gene (Enho gene) expressed in the liver and brain (16). High Enho expression in the brain was found in the areas involved in the control of different behaviors and regulation of peripheral metabolism (16). Hepatic Enho expression is regulated by nutrition (16). Mice devoid of the Enho gene have increased adiposity and insulin resistance (17). An association between diet and adropin levels was observed in animals and humans $(8,16,24)$. ADR reduces food intake and decreases body weight in obese mice after intraperitoneal injection (16). Therefore, ADR taking part in metabolic adaptation and modulation of insulin sensitivity seems to be a regulating factor in energy homeostasis $(8,16)$. It protects the organism against hyperinsulinemia and hepatosteatosis leading to obesity (8). The serum ADR level was found to be significantly lower in diabetic than non-diabetic organisms $(3,27)$; nevertheless, a higher serum ADR concentration was demonstrated in rats with streptozotocin-induced diabetes (1).

In addition to metabolic effects, ADR has non-metabolic properties, such as regulation of the endothelial function. ADR appears to be a novel regulator of the endothelial function via upregulation of endothelial nitric oxide synthase through activation of VEGFR-PI3K-Akt and VEGFR-PI3K-ERK1/2 pathways (18). Thus, ADR can play a role in the development of cardiovascular diseases.

Data from limited studies have indicated that ADR is expressed in the central nervous system, kidneys, heart, umbilical vein, coronary arteries, and gastrointestinal tissues: e.g. liver, pancreas, and intestines $(1,15,18)$. As reported by Aydin et al. (1), the largest amount of adropin has been detected in the pancreas. It appears that the gastrointestinal tissue is an important source of ADR. In the small intestine, ADR immunoreactiv- 
ity was detected earlier in smooth muscle and Paneth cells $(15,16)$. However, the data on the localization of adropin in the gastrointestinal tract are very limited. Moreover, there is no information about the role of adropin in the function of the stomach and intestines. Hence, the present study had the aim of investigating immunohistochemically the occurrence and distribution of ADR in the small intestine in rats in normal conditions and after removal of the stomach.

\section{Material and methods}

Animal procedures. All procedures using animals complied with the Guiding Principles for Research Involving Animals and were carried out with the agreement of the Local Ethics Committee for animal experiments. Twelve male Wistar rats aged 2.5 months with an initial body weight of approximately 220-240 g were used in the experiment. First, the rats were adapted to the conditions of the animal house for 7 days. The animals were kept under a controlled temperature of $22^{\circ} \mathrm{C}( \pm 10 \%)$ and humidity of $55 \%( \pm 10 \%)$ with a $12 \mathrm{~h}$ day/night cycle. The rats were provided water and LSM Standard Rat and Mouse chow ad libitum. After the acclimatization period, the rats were randomly divided into control and experimental groups.

Experimental design. Surgical operations were performed under general anesthesia with an injection ketamine, $15 \mathrm{mg} / \mathrm{kg}$ b.w. i.m. (Biowet-Pulawy, Poland), and Rometar, 35 $\mathrm{mg} / \mathrm{kg}$ b.w. i.m. (Leciva, Czech Republic). Six control rats (SHO) underwent a sham operation, i.e. an abdominal mid-line incision followed by gentle manipulation of the viscera. Six rats were subjected to gastrectomy $(\mathrm{GX})$, i.e. resection of the antrum and the glandular part of the stomach followed by joining the stomach pylorus to the nonglandular part of the stomach end-to-end. After the surgery, an antibiotic cover was applied for 3 days. Six weeks after the surgical procedures, the rats were fasted for $24 \mathrm{~h}$, anaesthetized by $\mathrm{CO}_{2}$ overdose inhalation, and euthanized

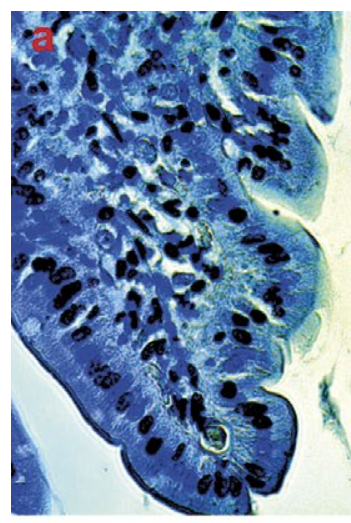

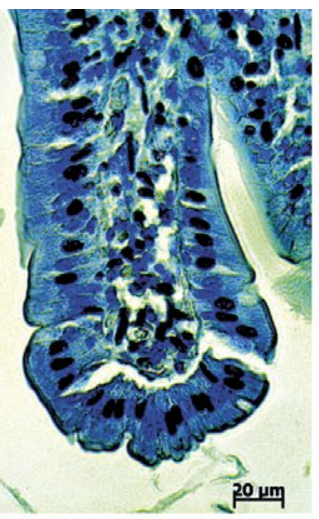
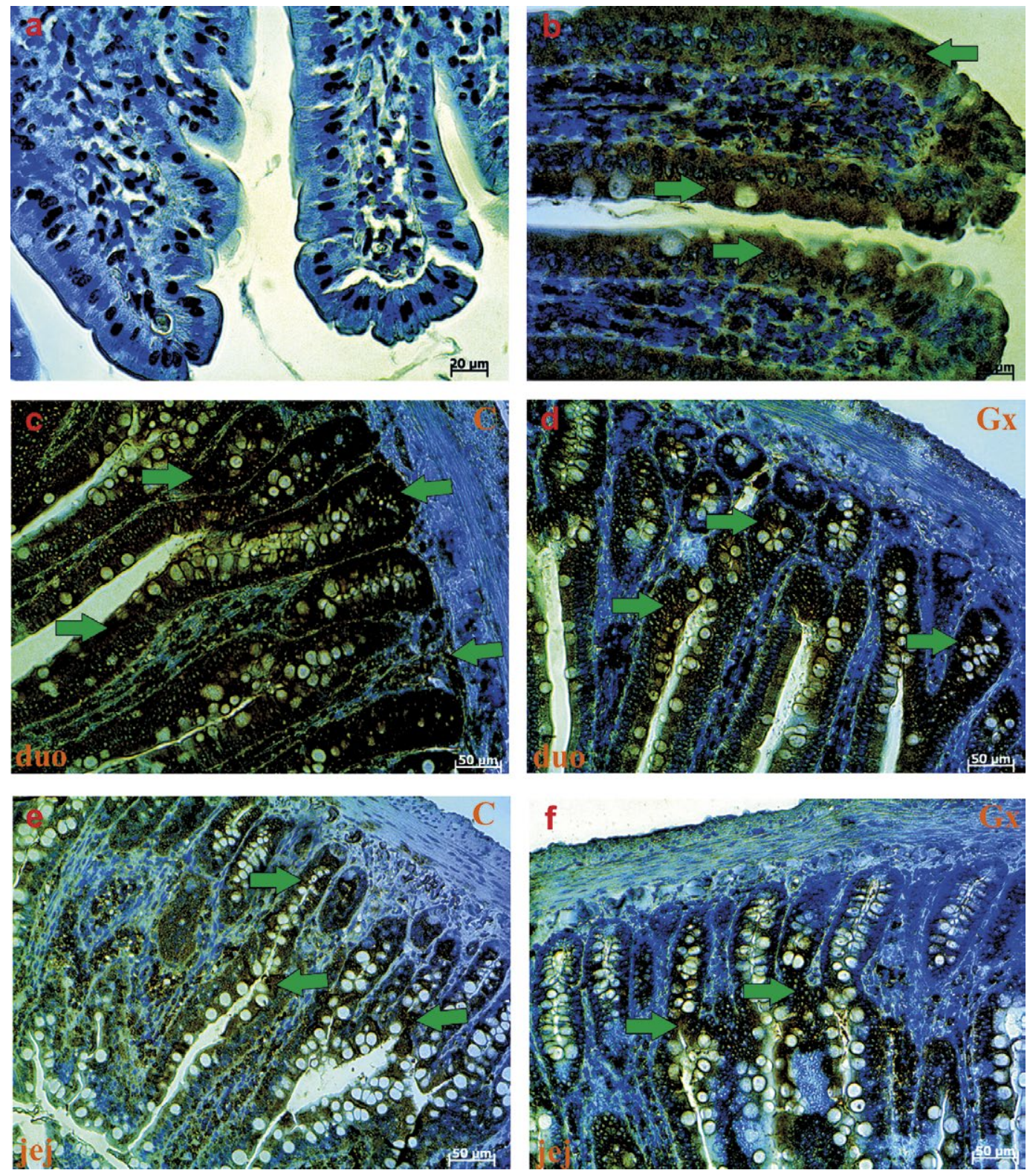

Fig. 1. ADR immunoreactivity in the duodenum (duo - b mag. 200×, c, d mag. 100×) and jejunum (jej - e, f, mag. 100 $\times$ ) in the control rats (C) and after gastrectomy (Gx). Brown color and the green arrow show positive ADR immunoreactivity. Negative controls (a, mag. 200 $\times$ ) - omission of primary antibody 
incubation at $4{ }^{\circ} \mathrm{C}$ with primary rabbit polyclonal antibody against adropin (Abcam, Germany, dilution $1: 100$ ) and secondary antibody Alexa Fluor 555 goat anti-rabbit IgG (Life Technologies, dilution $1: 50$ ) was applied for $2 \mathrm{~h}$. Finally, the slides were examined under a confocal microscope Olympus Fluoview FV1000 (Olympus, Japan). The negative control followed the above-mentioned procedure, but phosphate buffered saline (PBS) was used instead of primary antibodies (without adropin antibody).

Adropin immunohistochemistry staining (IHC). The paraffin sections were deparafinized, washed in graduated alcohol series, heated in a pressure cooker for $10 \mathrm{~min}$ in a citrate buffer solution $\mathrm{pH} 6$ for antigen retrieval, and washed with PBS three times for 5 min each time. After washing, a hydrogen peroxide block was used for $10 \mathrm{~min}$ as well as three-times wash with PBS; later, the sections were treated with an Ultra V Block solution (ThermoFisher Scientific, USA) to prevent background staining. The sections were incubated with primary rabbit polyclonal antibodies (anti-adropin antibody, diluted $1: 100$ ) for 12 hours at a fridge temperature. Next, the sections were washed with PBS three times for 5 min, incubated with HRP Polymer Quanto (ThermoFischer Scientific, USA) for $10 \mathrm{~min}$, and left in PBS. After applying drops of DAB Quanto Chromogen with Dab Quanto Substrate (detected using the Ultra Vision Quanto Detection System HRP -ThermoFischer Scientific, USA), the tissues were washed with PBS. The sections were counterstained with Mayer's hematoxylin, rinsed in PBS and distillated water, and mounted with a closure solution. To control the immunoreactivity, a negative control excluding primary antibodies was prepared. The preparations were examined using a Zeiss microscope (Carl Zeiss Germany) and photographed. The IHC evaluation of the resulting staining was expressed numerically as positive $(+1,+2,+3)$. In addition to the adropin labeling procedure described above, S100 Mouse Monoclonal Antibody (Cell Marque, USA), a Detection system Bright Vision+PolyAP-Anti Mouse/Rabbit IgG Biotin-free (Immunologic, Netherlands), and a Permanent Red Chromogen Kit (Cell Marque, USA) were used for visualization of the neuronal structure in the digestive system.

\section{Results and discussion}

The immunohistochemical and immunofluorescence staining for ADR and negative controls (omission of primary antibody and ADR immunoreactivity) are shown in figures 1 and 2. An immunopositive reaction to ADR was detected in the duodenum (Fig. 1c, d) and jejunum (Fig. 1e, f), in crypts and enterocytes located along the entire length of the villi (Fig. 1b). Furthermore, more intense ADR immunoreactivity was observed in the crypts and villi of the duodenum (Fig. 1c) than in the jejunum (Fig. 1e). ADR immunoreactivity was also seen in submucosa and muscularis externa in the duodenum and jejunum. The presence of adropin was detected in the cells of Brunner's gland of the duodenum (Fig. 2c) and in the myenteric and submucosal plexus nerve, covering Auerbach (Fig. 2d) and Meissner structures (Fig. 2a).

The ADR immunoreactivity in the crypts and villi in the duodenum was lower in the Gx rats $(+2)$ (Fig. 1d), compared to the SHO rats, where higher immunoreactivity at the level +3 was observed (Fig. 1c). Significantly lower ADR immunoreactivity at the level +1 was also detected in the crypts and villi of the jejunum in the Gx rats (Fig. 1f), compared to the SHO group characterized by slightly higher immunoreactivity at the level +2 (Fig. 1e). The ADR localization in the duodenum and jejunum was also confirmed in the immunofluorescence studies (Fig. 2b).
Fig. 2. Immunohistochemistry (a, c, d) and immunofluorescence (b) staining of ADR (green arrow) in a fragment of the duodenum with Brunner's glands (red arrow) (c), submucosal plexus nerve (yellow arrow, a), and myenteric plexus nerve (white arrow, d) (mag. 200×) 
In this paper, we described the ADR expression pattern in the rat small intestine. Kumar et al. (16) were the first to report that ADR is synthesized by smooth muscle cells. In our studies, we observed that intestinal smooth muscle cells were positive to adropin, which is consistent with previous results shown by Aydin et al. (1) and Kologulu et al. (15). Kologulu et al. (15) demonstrated intense adropin staining in Paneth cells in the basal parts of intestinal glands of the human small intestine. As indicated by these authors, Paneth cells synthesize adropin in addition to many other molecules (4). We also observed high immoreactivity to adropin in Paneth cells. Moreover, our IHC and IF analyses demonstrated that ADR was located not only in the crypts, but also along the entire length of the villi in enterocytes, duodenal glands, and ganglia. Therefore, we detected positive immunoreactivity to ADR in all histological layers (mucosa, submucosa, muscularis externa).

The gut is a source of different hormones, e.g. ghrelin, obestatin, and nesfatin-1, that play key roles in digestive functions as well as regulation of energy balance. Nesfatin-1 immunoreactivity has been reported in Brunner's glands of the duodenum and in the other parts of small and large intestines in rats and mice (19, $21,22,29)$. In pigs, nesfatin-1 immunoreactivity was described in the entire the gastrointestinal tract with localization in the endocrine cells of the gastric fundus, duodenum, ileum, ileocecal valve, and colon (25). In dogs, nesfatin-1 was only detected in the stomach and pancreas, but nesfatin-1 mRNA was detected in the entire gastrointestinal tract (13). Obestatin and ghrelin are present in the stomach, duodenum, jejunum, colon, and pancreas $(7,9,14,30)$. Immunoreactive cells for obestatin and ghrelin are numerous in the stomach, less abundant in the duodenum, occasional in the jejunum, and rare in the ileum (9). A large number of these cells were found in the crypts, whereas only a few were seen in the Brunner's gland. The overwhelming majority of these cells were located in the deeper third of the glands (9).

In our study, we found a stronger immunohistochemical reaction to ADR in the control than gastrectomized rats. At present, these results are difficult to explain. Bariatric surgery, including Gx, is performed in obese individuals to reduce body weight. Moreover, Gx is the predominant therapy for stomach-associated diseases. As shown by research, obesity is connected with decreased expression of the ADR transcript in the liver and low plasma concentrations of ADR (16, 17). In turn, after Roux-en-Y gastric bypass (RYGB), the plasma concentration of ADR increases (2). The increase in plasma ADR was connected with positive changes in markers of metabolic risk. This proves that ADR is required for maintenance of metabolic homeostasis, specifically for prevention of dyslipidemia and protection against impaired glucose tolerance associated with obesity. In the current literature, there are studies demonstrating an increase in ADR immunoreactivity in different tissues in diabetic animals $(1,15)$. It seems that this augmentation of ADR immunoreactivity may be a compensatory mechanism against tissue damage. In the present study, we observed reduced ADR immunoreactivity in the small intestine after Gx. It is difficult to explain whether this is a positive or negative change, especially given the lack of ADR plasma concentrations, which is the main limitation of the study.

Many investigations indicate changes in the plasma concentration of other hormones produced by digestive cells after bariatric surgery. Lower concentrations of obestatin and higher concentrations of ghrelin were observed in the plasma of obese subjects $(11,12)$. In a study conducted by Dogan et al. $(5,6)$, ghrelin and nesfatin-1 concentrations increased gradually and obestatin concentrations decreased within 6 months of the postoperative period after laparoscopic sleeve gastrectomy (LSG). In turn, an increase in the ghrelin concentration was observed only since the $6^{\text {th }}$ month after LSG (10). It is believed that this postoperative elevation in ghrelin occurs as a result of increased production thereof in extra-gastric sources, including the duodenum. The study reported by Wang et al. (26) confirmed the importance of duodenal ghrelin production. The duodenal compensative secretion of ghrelin was more effective after subtotal Gx in conditions of anatomical-physiological continuity, i.e. gastroduodenal anastomosis, compared to gastrojejunal anastomosis. In a study conducted by Huda et al. (12), ghrelin and obestatin levels were lower in Gx individuals, but the obestatin concentration after Gx was higher than in healthy controls. As in the case of ghrelin, this suggests other sites of obestatin secretion in the conditions of stomach removal. In a study performed by $\mathrm{Xu}$ et al. (28), plasma obestatin levels gradually increased after RYGB in comparison to SHO rats. Moreover, the expression of obestatin was significantly higher in the intestine (jejunum and ileum) in the RYGB animals than the SHO animals postoperatively (28). Moreover, obestatin staining in the intestine showed predominant distribution in the gland cells. However, another study reported that obestatin concentrations did not change after RYGB surgery in obese individuals (20). No changes in the ghrelin level and a reduced obestatin level were also observed (23). These data indicate that different bariatric surgery methods exert different effects on hormone levels.

In conclusion, our data demonstrated ADR expression in all histological layers of the small intestine in rats. Gx reduced ADR immunoreactivity in the crypts and enterocytes. This may suggest a potential impact of ADR on intestine functions such as absorbability and immune reactions. However, further research is needed to explain the ADR role in gastrointestinal functions. So far, there have been no reports on the location of ADR in the digestive tract in other animal species. 


\section{References}

1. Aydin S., Kuloglu T., Aydin S., Eren M. N., Yilmaz M., Kalayci M., Sahin I., Kocaman N., Citil C., Kendir Y.: Expression of adropin in rat brain, cerebellum, kidneys, heart, liver, and pancreas in streptozotocin induced diabetes. Mol. Cell Biochem. 2013, 380, 73-81.

2. Butler A. A., Tam Ch. S., Stanhope K. L., Wolfe B. M., Ali M. R., O'Keeffe M., St-Onge M.-P., Ravussin E., Havel P. J.: Low circulating adropin concentrations with obesity and aging correlate with risk factors for metabolic disease and increase after gastric bypass surgery in humans. J. Clin. Endocrinol. Metab. 2012, 97, 10, 3783-3791.

3. Celik E., Yilmaz E., Celik O., Ulas M., Turkcuoglu I., Karaer A., Simsek Y., Minareci Y., Aydin S.: Maternal and fetal adropin levels in gestational diabetes mellitus. J. Perinatal Med. 2013, 41, 375-380

4. Clevers H. C., Bevins C. L.: Paneth cells: maestros of the small intestinal crypts. Ann. Rev. Physiol. 2013, 75, 289-311.

5.Dogan U., Bulbuller N., Cakir T., Habibi M., Mayir B., Koc U., Aslaner A. Ellidag H. Y., Gomceli I.: Nesfatin-1 hormone levels in morbidly obese patients after laparoscopic sleeve gastrectomy. Eur. Rev. Med. Pharmacol. Sci. 2016 20, 1023-1031.

6.Dogan U., Ellidag H. Y., Aslaner A., Cakir T., Oruc M. T., Koc U., Mayir B., Gomceli I., Bulbuller N., Yilmaz N.: The impact of laparoscopic sleeve gastrectomy on plasma obestatin and ghrelin levels. Eur. Rev. Med. Pharmacol. Sci. 2016, 20, 2113-2122.

7. Dornonville de la Cour C., Bjorkqvist M., Sandvik A. K., Bakke I., Zhao C. M., Chen D., Hakanson R.: A-like cells in the rat stomach contain ghrelin and do not operate under gastrin control. Regul. Pept. 2001, 99, 141-150.

8. Ganesh Kumar K., Zhang J., Gao S., Rossi J., McGuinness O. P., Halem H. H. Culler M. D., Mynatt R. L., Butler A. A.: Adropin deficiency is associated with increased adiposity and insulin resistance. Obesity (Silver Spring) 2012, 20 1394-1402.

9. Grönberg M., Tsolakis A. V., Magnusson L., Janson E. T., Saras J.: Distribution of obestatin and ghrelin in human tissues: Immunoreactive cells in the gastrointestinal tract, pancreas, and mammary glands. J. Histochem. Cytochem. 2008, 56, 9, 793-801.

10. Hady H. R., Dadan J., Gotaszewski P., Safiejko K.: Impact of laparoscopic sleeve gastrectomy on body mass index, ghrelin, insulin and lipid levels in 100 obese patients. Videosurgery Miniinv. 2012, 7, 251-259.

11. Haider D. G., Schindler K., Prager G., Bohdjalian A., Luger A., Wolzt M., Ludvik B.: Serum retinol-binding protein 4 is reduced after weight loss in morbidly obese subjects. J. Clin. Endocrinol. Metab. 2007, 92, 1168-1671.

12. Huda M. S., Durham B. H., Wong S. P., Deepak D., Kerrigan D., McCulloch P. Ranganath L., Pinkney J., Wilding J. P.: Plasma obestatin levels are lower in obese and postgastrectomy subjects, but do not change in response to a meal. Int. J. Obes. (Lond.) 2008, 32, 129-135.

13.Jiang S., Zhou W., Zhang X., Wang D., Zhu H., Hong M., Gong Y., Ye J., Fang F: Developmental expression and distribution of nesfatin-1/NUCB2 in the canine digestive system. Acta Histochem. 2016, 118, 90-96.

14. Korbonits M., Goldstone A. P., Gueorguiev M., Grossman A. B.: Ghrelin a hormone with multiple functions. Front. Neuroendocrinol. 2004, 25, 27-68

15. Kuloglu T., Aydin S.: Immunohistochemical expressions of adropin and inducible nitric oxide synthase in renal tissues of rats with streptozotocin-induced experimental diabetes. Biotech. Histochem. 2014, 89, 2, 104-110.

16. Kumar K. G., Trevaskis J. L., Lam D. D., Sutton G. M., Koza R. A., Chouljenko V. N., Kousoulas K. G., Rogers P. M., Kesterson R. A., Thearle M., Ferrante A. W., Mynatt R. L., Burris T. P., Dong J. Z., Halem H. A., Culler M. D., Heisler L. K., Stephens J. M., Butler A. A.: Identification of adropin as a secreted factor linking dietary macronutrient intake with energy homeostasis and lipid metabolism. Cell Metab. 2008, 8, 468-481.

17. Kumar K. G., Zhang J., Gao S., Rossi J., McGuinness O. P., Halem H. H., Culler M. D., Mynatt R. L., Butler A. A.: Adropin deficiency is associated with increased adiposity and insulin resistance. Obesity 2012, 20, 1394-1402.

18. Lovren F., Pan Y., Quan A., Singh K. K., Shukla P. C., Gupta M., Al-Omran M., Teoh H., Verma $S$. : Adropin is a novel regulator of endothelial function. Circulation 2010, 122, S185-192.

19. Ramesh N., Mortazavi S., Unniappan S.: Nesfatin-1 stimulates cholecystokinin and suppresses peptide YY expression and secretion in mice. Biochem. Biophys. Res. Commun. 2016, 472, 201-208.

20. Roth C. L., Reinehr T., Schernthaner G. H., Kopp H. P., Kriwanek S., Schernthaner $G$.: Ghrelin and obestatin levels in severely obese women before and after weight loss after Roux-en-Y gastric bypass surgery. Obes. Surg. 2009 , $19,29-35$.

21. Stengel A., Goebel M., Yakubov I., Wang L., Witcher D., Coskun T., Taché Y., Sachs G., Lambrecht N. W.: Identification and characterization of nesfatin-1 immunoreactivity in endocrine cell types of the rat gastric oxyntic mucosa. Endocrinol. 2009, 150, 232-238.
22. Stengel A., Hofmann T., Goebel-Stengel M., Lembke V., Ahnis A., Elbelt U., Lambrecht N. W., Ordemann J., Klapp B. F., Kobelt P.: Ghrelin and NUCB2/ nesfatin-1 are expressed in the same gastric cell and differentially correlated with body mass index in obese subjects. Histochem. Cell Biol. 2013, 1, 909-918

23. Stenström B., Furnes M. W., Tømmerås K., Syversen U., Zhao C. M., Chen D. Mechanism of gastric bypass-induced body weight loss: one-year follow-up after micro-gastric bypass in rats. J. Gastrointest. Surg. 2006, 10, 1384-1139.

24. St-Onge M. P., Shechter A., Shlisky J., Tam C. S., Gao S., Ravussin E., Butler A. A.: Fasting plasma adropin concentrations correlate with fat consumption in human females. Obesity 2014, 22, 4, 1056-1063.

25. Varricchio E., Russolillo M. G., Russo F., Lombardi V., Paolucci M., Maruccio L.: Expression and immunohistochemical detection of nesfatin-1 in the gastrointestinal tract of Casertana pig. Acta Histochem. 2014, 116 583-587.

26. Wang H. T., Lu Q.-Ch., Wang Q., Wang R.-Ch., Zhang Y., Chen H. L., Zhao H., Qian H.-X.: Role of the duodenum in regulation of plasma ghrelin levels and body mass index after subtotal gastrectomy. World J. Gastroenterol. 2008, 14 $15,2425-2429$

27. Wu L., Fang J., Chen L., Zhao Z., Luo Y., Lin C., Lin F.: Low serum adropin is associated with coronary atherosclerosis in type 2 diabetic and non-diabetic patients. Clin. Chem. Lab. Med. 2014, 52, 751-758.

28. Xu X., Wang J., Li L., Wang C., Li W., Zhang Q., Yang L.: The role of obestatin in Roux-en-Y gastric bypass surgery in the obese, type 2 diabetes Zucker rat. Diabetes Res. Clin. Pract. 2016, 119, 57-64

29.Zhang A. Q., Li X. L., Jiang C. Y., Lin L., Shi R. H., Chen J. D., Oomura Y.: Expression of nesfatin-1/NUCB2 in rodent digestive system. World J. Gastroenterol. 2010, 16, 1735-1741.

30. Zhao C. M., Furnes M. W., Stenstrom B., Kulseng B., Chen D.: Characterization of obestatin- and ghrelin-producing cells in the gastrointestinal tract and pancreas of rats: an immunohistochemical and electron-microscopic study. Cell Tissue. Res. 2008, 331, 575-587

Corresponding author: Marta Pawłowska-Olszewska, DVM, PhD, Akademicka 12, 20-033, Lublin, Poland; e-mail: martapaw@autograf.pl 